\title{
Leisure Satisfaction and Life Satisfaction of Older Adults: The Effect of a Ten-week Recreation Program
}

\section{Nurullah Emir Ekinci', Utku Isik ${ }^{2}$, Umit Dogan Ustun3}

\author{
${ }^{1}$ Yalova University Faculty of Sports Science, Yalova, Turkey \\ ${ }^{2}$ Recep Tayyip Erdogan University School of Physical Education \\ and Sports, Rize, Turkey \\ ${ }^{3}$ Hatay Mustafa Kemal University School of Physical Education \\ and Sports, Hatay, Turkey \\ Study Area: Yalova, Turkey
}

\begin{abstract}
The study presents an insight from an Erasmus programme project named "Knowledge is power, age ain't matter!" conducted at Dumlupinar University. In the study, ten individuals participated and, to collect data as per leisure satisfaction scale and proper satisfaction with life scale were used. Analysed results showed significant differences between the pre and post-tests results. In conclusion, this study showed that the ten-week recreation programme positively affects both leisure and life satisfaction in individuals 50 and over.
\end{abstract}

Key words: Ageing, Lifestyle, Physical activity. technology, the shape of social life has changed, and this change has revealed different human needs (Williams, 2003). As a result of modern technology, the need for workforce reduced, and the leisure time for humans increased significantly for older adults (Wilpert, 2009; Heo et al., 2010; Keskin \& Bayram, 2018). According to researchers getting retirement and having more free time create some problems for the elderly (Glymour et al., 2010). Besides, according to the study of Marmot \&Bell (2012), most people lose the ability of a healthy lifestyle when they live long. Even though the general trend is for physical activity to decrease with age (Sun et al., 2013), relevant literature shows that participation in leisure activities can make valuable contributions to the elderly. According to Ekinci \& Özdilek (2019), participating in leisure activities provides individuals to have pleasure, to be social, and to develop themself. Paggi et al., (2016) mentioned that participation in leisure activities is associated with various components of successful aging, including physical health and well-being. Besides, previous research showed that involving in leisure activities decreases the risk of mortality and maintenance or prevention of further declines in physical health and functioning (Janke et al., 2006), helps to keep the person mentally, spiritually, and physically fit (Eskiler \& Karakas, 2017), helps to protect physical and psychological well-being also increase happiness (Menec, 2003), helps stress management (Walker et al., 1987) and, helps to increase the quality of life (Tsaur et al., 2012). The positive link between health and participation in exercise and leisure-time activities is well established (Carmichael et al., 2015). Individuals improve themselves physically, socially, and emotionally by participating in leisure

*Corresponding Author: ekinciemir@gmail.com 
activities (Tekin et al., 2009). However, despite the positive contributions of participation in leisure activities (Ekinci \& Özdilek 2019; Üstün \& Aktas Üstün, 2020; Yalcin et al., 2020), it has been seen that individuals do not participate in such activities, which are very important to them for different reasons, or various obstacles (Ekinci et al., 2014; Chow \& Dong, 2013). According to researchers having difficulty in managing time (Kowal \& Fortier, 2007), demographic features and lack of motivation (Üstün, 2018: 14) are among these obstacles. Rathnayaka et al., (2019) mentioned that some obstacles come over by aging; such as coronary heart disease, hypertension, diabetes mellitus, and osteoporosis. So, we can say that aging can prevent individuals from participating in leisure activities. That is why the primary purpose of this study was to examine the effect of a ten-week multiple enjoyable recreational games on leisure and life satisfaction in individuals 50 and over.

\section{Materials and Methods:}

The study presents insight from the ERASMUS+ Program registered under project number 2015-1-PLo1-KA204o16999. The name of the project was "Knowledge is power, age ain't matter!".The project was carried out at Dumlupinar University (Kutahya, Turkey). All participants voluntarily gave informed consent to participate in the trial after being informed about the purpose of the study. Those individuals who chose not to consent to participate did not have access to the survey questions. This study was applied to a total of 10 participants. The participants were all Turkish speakers (three male and seven female). The mean age of the group was 55.23 years $(S D=3.96)$. Expert medicine doctors examined all participants before starting the study, and their suitability for the activities to be performed was recorded.In the study to collect data in addition to personal information from Turkish versions of Beard \& Ragheb (1980) Leisure Satisfaction Scale and Diener et al., (1985)'s Satisfaction with Life scales were used. The original form of the Leisure satisfaction scale consisted of 51 items and six sub-dimensions as psychological, educational, social, relaxation, physiological, and aesthetics satisfaction. The answers given to the scale are evaluated with a 5 -point Likert type scale ( $1=$ rarely valid for me, 5 = almost always valid for me) (Beard \& Ragheb, 1980). Karli et al., (2008) adapted the scale into Turkish. Moreover, in the present study, we referenced Karli et al., (2008)'s study. Diener et al., initially developed the satisfaction with life scale in 1985 . The original form of the scale has 1 factor with five items which measure the individual's evaluation of satisfaction with life in general (e.g., "I am satisf ied with my life," and "If I could live my life over, I would change almost nothing"). Respondents select one of seven options (ranging from "strongly disagree" to "strongly agree") for each question. Responses were averaged to provide a total life satisfaction score. Dagli \& Baysal adapted the scale into Turkish in 2016. Moreover, in the present study, we used the
Turkish version, which was validated by Dagli \& Baysal (2016). After explaining the purpose of the study to the determined volunteers, the measures detailed above were filled (pre-test). Later, various recreational purpose activities-the visuals of which were given below-were applied to the participants in the game form. The applications were designed three days a week for at least half an hour for ten weeks. Before starting the games, the resting pulses of the participants were taken, and all games were designed to exceed the resting heart rates of the participants by $20 \%$ at most. After ten weeks of playing games, the measurement tools were filled again (post-test), and the differences between them were tried to be determined. Variables were log-transformed to reduce bias due to nonuniformity of error and analyzed using the effect size (ES) statistics with $95 \%$ confidence intervals (CI) and percent difference to determine the magnitude of effects using a custom spreadsheet (Hopkins et al., 2006). Magnitude-based inferences on differences within and between matches were made by standardizing differences using the between-subject SD. A paired sample t-test was used to determine the differences between pre and post-test. A paired sample t-test, in conjunction with the Cohen effect size, was used to compare changes in activities between the pre and post-test. Magnitudes of standardized effects were assessed as o-0.2 trivial, 0.2-0.6 small, o.6-1.2 moderate, 1.2-2.0 large, and >2.0 very large (Batterham \& Hopkins, 2006). The effect was reported as unclear when the $\mathrm{CI}$ of the standardized difference crossed the threshold for both substantially positive (o.2) and negative (-o.2) values (Cohen \& Will, 1985). The quantitative changes of finding differences were assessed as follows: $<1 \%$, almost certainly not; $1-5 \%$, very unlikely; $5-25 \%$, unlikely; $25-75 \%$, possible; $75-95 \%$, likely; $95-99 \%$, very likely; > 99\%, almost certain. The level of statistical signif icance was set at $\mathrm{p}=\mathbf{0 . 0 5}$

\section{Results:}

As a result of the analysis, significant differences were determined between the post-test and pre-test averages of the life satisfaction levels of the participants. Accordingly, the life satisfaction of the participants signif icantly differed as a result of 10-week recreational activities $(\mathrm{t}(12)=-4.745$; $\mathrm{p}<$.ool; Cohen's d; o.78). When looking at Cohen's d effect level, it can be said that a medium level effect had emerged. In addition, when the leisure time satisfaction scale subexamined of the participants. It was determined that significant differences emerged in the sub-dimensions of psychological $(t(12)=-3,284 ; p=.007$;Cohen's $d=1.08)$; relaxation $(\mathrm{t}(12)=-2.816 ; \mathrm{p}=.016$; Cohen's $\mathrm{d}=1.17)$ and aesthetic $(t(12)=-0.249 ; \mathrm{p}=.011 ;$ Cohen's $\mathrm{d}=0.95$. When looking at Cohen's d effect level. It was determined that the effect was moderated in all sub-dimensions. 
Table-1: Comparison of pre and post-test results ( $\mathrm{N}=10$, common)

\begin{tabular}{|c|c|c|c|c|c|c|c|}
\hline & M & $\mathrm{SD}$ & $t(12)$ & $\begin{array}{l}95 \% \text { CI } \\
\text { LL }\end{array}$ & UL & $\mathrm{p}$ & Cohen's d \\
\hline \multicolumn{8}{|c|}{ Life Satisfaction Test } \\
\hline Pre & 18.846 & 4.100 & $-4 \cdot 745$ & -1.914 & -1.747 & $<.001$ & 0.78 \\
\hline Post & 22.077 & 4.092 & & & & & \\
\hline \multicolumn{8}{|c|}{ Psychological Test } \\
\hline Pre & 3.474 & 0.541 & -3.284 & -0.986 & -0.199 & .007 & 1.08 \\
\hline Post & 4.067 & 0.551 & & & & & \\
\hline \multicolumn{8}{|c|}{ Educational Test } \\
\hline Pre & 4.427 & 0.464 & 0.136 & -0.383 & 0.435 & .894 & 0.04 \\
\hline Post & 4.402 & 0.623 & & & & & \\
\hline \multicolumn{8}{|c|}{ Social Test } \\
\hline Pre & 4.087 & 0.672 & -1.986 & -0.867 & 0.040 & .070 & 0.74 \\
\hline Post & $4 \cdot 500$ & 0.405 & & & & & \\
\hline \multicolumn{8}{|c|}{ Relaxation Test } \\
\hline Pre & 4.192 & 0.647 & -2.816 & -1.023 & -0.130 & .016 & 1.17 \\
\hline Post & 4.769 & 0.259 & & & & & \\
\hline \multicolumn{8}{|c|}{ Physiological Test } \\
\hline Pre & 3.987 & 0.607 & -1.092 & -0.614 & 0.204 & .296 & 0.40 \\
\hline Post & 4.192 & 0.378 & & & & & \\
\hline \multicolumn{8}{|c|}{ Aesthetic Test } \\
\hline Pre & 3.442 & 1.114 & -3.010 & $-1.55^{8}$ & -0.249 & .011 & 0.95 \\
\hline Post & 4.346 & 0.754 & & & & & \\
\hline
\end{tabular}

\section{Discussion:}

The world's population is aging rapidly. In 2019, about $9 \%$ of the global population was aged 65 or above. This proportion is estimated to reach $12 \%$ by 2030 and $16 \%$ by 2050 . Furthermore, projections indicate that the population of aged people will be twice as many as that of children aged o-4 and will exceed youths aged 5-14 and 15-24, respectively, by 2050 (Department of Economic Social Affairs, 2019).Most adults do not engage in regular physical activity, and individuals over the age of 50 are the most sedentary segment of the population (Harvet et al., 2013). Self-report data suggest only about $20 \%$ of all adults, and about $12 \%$ of adults over 65 , meet the official physical activity recommendations (Clarke et al., 2017). However, we know that leisure activities are essential to healthy aging, reducing the risk of cardiovascular disease, susceptibility to stress and depression, and improving cognitive functioning. Physical activity is an important modifiable risk factor for reducing the risk of dementia and cognitive decline in older age (Rovio et al., 2005; Hörder et al., 2018). Besides, agerelated loss of skeletal muscle (sarcopenia) led to decreased force production and increased fatigue, resulting in significant impairment in activities of daily living and a subsequent reduction in quality of life. Leisure scientists have long believed that leisure plays a role in benefiting overall well-being and buffering stress. This benefit may occur as the result of leisure encouraging positive feelings and promoting a variety of social and physical resources that allow individuals to feel refreshed and better cope with stress (Pressman et al., 2009). Taylor-Piliae et al., (2010) found that higher physical well-being was significantly related to older adults' intensity of physical activity. Janke et al., (2006) found in a sample of adults aged 50 and older that socializing with others significantly declined with increasing functional limitations and chronic illnesses.

Steady growth in the older population has resulted in increased interest by researchers in the role that lifestyle plays in shaping a right old age. There is a long and rich history of published work that examines the contribution of leisure to adult well-being, particularly to perceptions of life satisfaction in the older adult years (Andrews \& Withey, 1976; Carp \& Carp, 1982; Cutler \& Hendricks, 1990; Everard, 1999; Mcguire et al., 1987; Stanley \& Freysinger, 1995). More recently, there is new evidence that leisure activities contribute to cognitive reserve in the senior years and that cognitive reserve is fundamental to well-being (Scarmeas \& Stern, 2003; Scarmeas et al., 2001).

Beyond just the issue of leisure, participation is the issue of leisure satisfaction. Riddick (1985), Brown \& Frankel (1993) found that leisure satisfaction contributed to overall life satisfaction in older adults. Riddick (1986) also examined changes in leisure satisfaction between age groups and gender using the Leisure Satisfaction Scale. Her findings indicated that different age groups and differences in gender did not impact leisure satisfaction. Russell (1984) studied the relationship of specific circumstances of life and retirement satisfaction and the role of frequency of leisure activity participation and satisfaction with leisure in retirement satisfaction. She utilized multiple instruments in her study, including the Leisure Satisfaction Scale, to measure leisure satisfaction. She found a significant correlation between leisure satisfaction and retirement satisfaction. As the population of older adults increases, so does the interest in understanding the aging process and enhancing the quality of life. The aging population creates many new challenges and changes in society (Butler \& Bowlby, 1997). The socio-demographic changes have direct implications for the leisure industry, providing programs for older adults (Tedrick \& MacNeil, 1991). The age of the individuals is playing an active role in participating in recreational activities. When the preferred recreational activities are examined, we see that as the age increases, the level of interest of the individuals in the activities changes as well (Aslan \& Aslan Cansever, 2012).Leisure is a significant component in the daily well-being of an individual. Daily activities such as work, cleaning, or sleeping do not necessarily contribute to increased happiness. While, leisure activities, which are usually freely chosen and intrinsically motivated, may provide more opportunities for pleasure, and as a result, increase overall life satisfaction (Edginton et al., 1998). Besides, as people age, leisure activity can extend the years of living independently, decrease disability, and enhance the overall quality of life (Aldrich, 2004).As a result of the analysis, the recreational activities participated in for ten weeks had a 
moderate effect on life satisfaction among older adults. We also found significant differences in leisure satisfaction levels. Especially in psychological, relaxation, aesthetic subdimensions, the results were found to be much more significant among the older adults of the recreational activities. The emergence of significant differences in these sub-dimensions shows us that psychological satisfaction was more than physical satisfaction. Research supports the overall correlation between life and leisure satisfaction (Brown \& Frankel, 1993). Several studies examining leisure and life satisfaction have shown that satisfaction with leisure is the most significant determinant of well-being, more so than other aspects of life. Hemingway (1996) mentioned that the quality of life of individuals increases with the free time activities provided in the community. These studies reveal the importance of the need for recreation. Recreational activities should be carried out consciously for this need to be met entirely. Recreational activities that are carried out deliberately will offer significant gains both to the individual and to the society (Ekinci \& Ozdilek, 2019). There is evidence that physical health affects participation in leisure activities and that both physical health and activities affect well-being (Paggi et al., 2016). According to Ekinci \& Yalcin (2019), sportive recreational areas will enable individuals to participate in more recreational activities. The results of these studies confirmed our hypothesis that the links between life satisfaction and leisure satisfaction were enhanced in the presence of leisure activities as a mediator, supporting the primary effect model, where adults with higher quality social relationships such as leisure activity. Overall, findings from the present study have several potential implications for supporting optimal life and leisure satisfaction in this population, which should be explored in future research.

\section{References:}

Aldrich, N. (2004): CDC targets sedentary older adults. Aging Today, 25(1): 7-8

Andrews, F.M. \& Withey, S.B. (1976): Social indicators of wellbeing: Americans' perceptions of life quality. Pub. by: Plenum Press, New York, NY.

Aslan, N. \& Aslan Cansever, B. (2012): Leisure time perception of adolescents. Hacettepe Uni.J. Edu., 42:23-25.

Batterham, A.M. \& Hopkins, W.G. (2006): Making meaningful inferences about magnitudes. Int. J. Sports Physiol. Performance: 1(1):50-57.

Beard, J.G. \& Ragheb, M.G. (1980): Measuring leisure satisfaction. J. Leisure Res., 12(1):20-33.

Brajša-Žganec, A., Merkaš, M. \& Šverko, I. (2011): Quality of life and leisure activities: how do leisure activities contribute to subjective well-being? Soc. Indicat. Res., 102(1):81-91.

Brown, B.A. \& Frankel, B.G. (1993): Activity through the years: leisure, leisure satisfaction, and life satisfaction. Soc. Sport J., 10:1-17.

Butler, R. \& Bowlby, S. (1997): Bodies and spaces: an exploration of disabled people's experiences of public space. Envi. Plan. D: Soc. Space, $15(4): 411-433$.

Carmichael, F., Duberley, J. \& Szmigin, I. (2015): Older women and their participation in exercise and leisure-time physical activity: the double-edged sword of work. Sport Soci. 1(18):42-6o.

Carp, F. \& Carp, A. (1982): Test of a model of domain satisfactions and well-being. Res. Aging, 4(4):503-522.

Chow, H. \& Dong, Y.H. (2013): Relationship between participation in leisure activities and constraints on Taiwanese breastfeeding mothers during leisure activities. BMC Pub. Health, 13(410).

Clarke, T.C., Norris, T. \& Schiller, J.S. (2017): Early release of selected estimates based on data from the 2016 National Health Interview Survey. Pub. by: National Center for Health Statistics, Washington, DC.

Cohen, S. \& Wills, T.A. (1985): Stress, social support, and the buffering hypothesis. Psychol. Bull., 98:310-357.

Cutler, S.J. \& Hendricks, J. (1990): Leisure and time use across the life course (pp. 169-185). In, Binstock, R. H. \& George, L. K. (Eds.): Handbook of Aging and the Social Sciences. Pub. by:Academic Press, New York, NY.

Dağlı, A. \& Baysal, N. (2016): Adaptation of the satisfaction with life scale into turkish:the study of validity and reliability. Electron.J. Soc. Sci., 15(59).

Department of Economic Social Affairs. (2019): World Population Prospects (Highlights). Pub. by: United Nations, New York, NY.

Diener, E.D., Emmons, R.A., Larsen, R.J. \& Griffin, S. (1985): The satisfaction with life scale. L. Person. Assess., 49(1):71-75.

Edginton, C.R., Jordan, D.J., De Graaf, D.G. \& Edginton, S.R. (1998): Leisure and Life Satisfaction: Foundational Perspectives (2nd ed.).Pub. by: McGraw-Hill; Boston, MA.

Ekinci, N.E. \& Ozdilek, C. (2019): Investigation of university students' awareness of recreational activities. Int. Online I. Edu. Sci., 11(2):53-66.

Ekinci, N.E., Kalkavan, A., Üstün, Ü.D. \& Gündüz, B. (2014): Investigation of factors that may constrain participation of sportive and non- sportive recreational activities among university students. Sportive View:J. Sport Edu. Sci.,1(1):1-13.

Ekinci, N.E. \& Yalcin, H. (2019): Leisure involvement level of 40 and over-aged individuals. J. Edu. Issues, 5(2):170-181.

Eskiler, E. \& Karataş, G. (2017): Investigating the relationships between leisure-time behaviors and behavioral intentions of Sakarya University students. Istanbul Univers. J. Sport Sci. 7(3):10-24.

Everard, K.M. (1999): The relationship between reasons for activity and older adult well-being. L. Appl. Gerontol., 18(3):325-340.

Glymour, M.M., Mujahid, M., Wu, Q., White, K. \& Tchetgen, E.J.T. (2010): Neighborhood disadvantage and self-assessed health, disability, and depressive symptoms: longitudinal results from the health and retirement study. Ann. Epidemiol., 20(11):856-861.

Hemingway, J.L. (1996): Emancipating leisure: the recovery of freedom in leisure. L. Leisure Res., 28(1):27-43.

Heo, J., Lee, Y., Pedersen, P.M. \& McCormick, B.P. (2010): Flow 


\section{ORIGINAL ARTICLE}

experience in the daily lives of older adults: an analysis of the interaction between flow individual differences serious leisure location and social context. Can. J., 29(3):411-423.

Hopkins, W., Marshall, S., Batterham, A. \& Hanin, J. (2009): Progressive statistics for studies in sports medicine and exercise science. Med.Sci. Sports Exer., 41(1):3-13.

Hörder, H., Johansson, L., Guo, X., Grimby, G., Kern, S. \& Östling S. (2018): Midlife cardiovascular fitness and dementia. Neurol., 90:e1298.

Janke, M., Davey, A. \& Kleiber, D. (2006): Modeling change in older adults' leisure activities. Leisure Sci., 28(3):285-303.

Juliusson, G., Karlsson, K., Lazarevic, V.L., Wahlin, A., Brune, M., Antunovic, P. ... \& Möllgård, L. (2011): Hematopoietic stem cell transplantation rates and long-term survival in acute myeloid and lymphoblastic leukemia: real-world population-based data from the Swedish acute leukemia registry 1997-2006. Cancer, $117(18): 4238-4246$.

Karlı, Ü., Polat, E., Yılmaz, B. \& Koçak, S. (2008): Reliability and validity study of leisure satisfaction scale (Lss-long version).L. SportSci., 19(2):80-91.

Keskin, U. \& Bayram, A. (2018): Evaluation of recreative activities in the context of classification of consumption products. Sportive View:J. Sport Edu. Sci., 5(SI1):1-13.

Kleijnen, M., De Ruyter, K. \& Wetzels, M. (2007): An assessment of value creation in mobile service delivery and the moderating role of time consciousness. L. Retail., 83(1):33-46.

Kowal, J. \& Fortier, M.S. (2007): Physical activity behavior changes in middle-aged and older women: the role of barriers and of environmental characteristics. L. Behav. Med., 30(3):233-242.

Marmot, M. \& Bell, R. (2012): Fair society, healthy lives. Pub. Health, 126:4-10.

Mcguire, F.A., Dottavio, F.D. \& O'Leary, J.T. (1987): The relationship of early life experiences to later life leisure involvement. Leisure Sci., 9:251-257.

Menec, V.H. (2003): The relation between everyday activities and successful aging: a 6-year longitudinal study. L. Gerontol., 58:74-82.

Paggi, M.E., Jopp, D. \& Hertzog, C. (2016): The importance of leisure activities in the relationship between physical health and well-being in a life span sample. Gerontol., 62(4):450-458.

Pressman, S.D., Matthews, K.A., Cohen, S., Martire, L.M., Scheier, M., Baum, A. \& Schulz, R. (2009): Association of enjoyable leisure activities with psychological and physical well-being. Psychosom. Med., 71(7):725-732.

Rathnayaka, H., Geethanjana, P., Gamage, U., Karunarathne, H. \& Jayathilaka, R. (2019): Socio-demographic characteristics of recreatinal activities: evidence from eastern province. Pub. in: Vavuniya Campus International Research Symposium (VCIRS-2019).

Riddick, C.C. (1985): Life satisfaction determinants of older males and females. Leisure Sci., 7:47-63.

Riddick, C.C. (1986): Leisure satisfaction precursors. J. Leisure Res., 18(4):259-265

Rovio, S., Kåreholt, I., Helkala, E., Viitanen, M., Winblad, B. \& Tuomilehto, J. (2005): Leisure-time physical activity at midlife and the risk of dementia and Alzheimer's disease.
Ambient Science, 2020: Vol. 07(Sp1); 102-106 DOI:10.21276/ambi.2020.07.sp1.oa11

Lancet Neurol., 4:705-711.

Russell, R.V. (1984): Correlates of life satisfaction in retirement. Unpublished doctoral dissertation. Indiana University, Bloomington, IN.

Sala, G., Jopp, D., Gobet, F., Ogawa, M., Ishioka, Y., Masui, Y....\&Gondo, Y. (2019): The impact of leisure activities on older adults' cognitive function, physical function, and mental health. PloSOne, 14(11):e0225006.

Scarmeas, N., Levy, G., Tong, M.X., Manly, J. \& Stern, Y. (2001): Influence of leisure activity on the incidence of Alzheimer's disease. Neurol., 57:2236-2242.

Scarmeas, N. \& Stern, Y. (2003): Cognitive reserve and lifestyle. L. Cli. Experi. Neuropsychol., 25:625-633.

Stanley, D. \& Freysinger, V.J. (1995): The impact of age, health, and sex on the frequency of older adults' leisure activity participation: a longitudinal study. Act. Adap. Aging, 19(3):31-42.

Sun, F., Norman, I.J. \& While, A.E. (2013): Physical activity in older people: a systematic review. BMC Public Health, 13(1):449.

Taylor-Piliae, R.E., Newell, K.A., Cherin, R., Lee, M.J., King, A.C. \& Haskell, W.L. (2010): Effects of Tai Chi and Western exercise on physical and cognitive functioning in healthy community-dwelling older adults. J. Aging Phys. Act. 18(3):261-279.

Tedrick, T. \& MacNeil, R.D. (1990): Sociodemographics of older adults: Implications for leisure programming. Act. Adapt. Aging, 15(3):73-92.

Tekin, G., Amman, M.T. \& Tekin, A. (2009): The effect of recreational physical exercise on depressionand assertiveness levels of university students. Int. J. Human Sci., 6(2):148-159.

Tsaur, S.H., Liang, Y.W. \& Hsu, H.J. (2012): A multidimensional measurement of work-leisure conflict. Leisure Sci., 34(5):395-416.

Üstün, Ü.D. (2018): Introduction to Recreation. Pub. by: Ergun Publishing House, Izmir.

Üstün, Ü.D. \& Aktaş Üstün, N. (2020): Investigation of university students' realization of the benefits of leisure activities. Sportive Look: J. Sport Edu. Sci., 7(SI1):38-48.

Verbrugge, L.M., Gruber-Baldini, A.L. \& Fozard, J.L. (1996): Age differences and age changes in activities: Baltimore longitudinal study of aging. Sci. Soc. Sci., 51(1):30-41.

Walker, S.N., Sechrist, K.R. \& Pender, N.J. (1987): The healthpromoting lifestyle profile: development and psychometric characteristics. Nurs. Res., 36(2):76-8o.

Williams, R. (2003): The technology and the society. Tele: Critical Conc. Media Cul.Stud., 2:42.

Wilpert, B. (2009): Impact of globalisation on human work. Safety Science, $47(6): 727-732$.

World Health Organization (WHO). (2006): The world health report 2006: working together for health. Pub. by: WHO

Yalcin, I., Araz, G.Y., Ekinci, N.E. \& Birkok, M.C. (2020): The effect of sports attitude on healthy lifestyle behavior in university students. Prog. Nutri., 22:66-71. 